\title{
Comparison of Detection of Antibodies with Yeast Lysate Antigens Prepared from Two Isolates of Blastomyces dermatitidis by Two Different Methods: Sensitivity and Specificity Evaluations
}

\author{
Tiffany R. Allison, Gene M. Scalarone \\ Department of Biological Sciences, Idaho State University, Pocatello, USA \\ Email: allitiff@isu.edu
}

Received October 15, 2012; revised November 17, 2012; accepted November 29, 2012

\begin{abstract}
Blastomycosis, a systemic fungal disease, caused by the dimorphic fungus Blastomyces dermatitidis, has continually presented clinicians with concerns with regard to laboratory diagnosis and prevention. For years researchers have strived to develop antigens with a high degree of sensitivity and specificity. The purpose of this study was to gain a better understanding of how two novel yeast lysate antigens, prepared from two B. dermatitidis isolates by different methods, would be able to detect antibody responses in immunized rabbits in a specific and sensitive manner. The enzyme-linked immunosorbent assay (ELISA) was used to evaluate antibody in serum specimens with yeast lysate reagents prepared after allowing yeast cells to lyse for 1 or 7 days. The results indicated that reactivity was greater with the day 7 antigens, with both the B5896 and 597 B. dermatitidis isolates, when compared to the day 1 antigens; in contrast the day 1 preparations exhibited less cross reactivity when assayed against anti-Histoplasma capsulatum serum specimens.
\end{abstract}

Keywords: Isoelectric Focusing; ELISA; Blastomycosis; Lysate Antigen; Antibody Detection

\section{Introduction}

The systemic dimorphic fungal disease, blastomycosis, caused by Blastomyces dermatitidis, occurs in humans and other animals. Blastomycosis is a disease found mainly in North America as a soil saprophyte associated with sandy slightly acidic soils often found near a water source. The disease may also occur in other locations including certain regions of Africa and India [1-3]. B. dermatitidis is a thermally dimorphic fungus which is acquired by inhalation of the mycelial spore into the lung which converts to a yeast cell and produces a primary pulmonary infection. It may disseminate into other organs of the body including the meninges and cutaneous lesions may also develop as the disease progresses [4-8]. Current laboratory diagnostic methods include direct visualization histologic, cytologic or culturing the organism. In certain instances these techniques may not provide a reliable diagnosis or possibly a misdiagnosis [9-11].

In recent years investigators have made substantial contributions with regard to the development and evaluation of immunodiagnostic assays that are sensitive and specific $[9,10,12-18]$. Our laboratory has been involved in the production and comparative studies of B. dermatitidis yeast lysate antigens, prepared from various isolates of the fungus for the detection of antibodies in sera from immunized and infected animals [19-27]. Previous studies were conducting using day 7 lysates, recent evidence has indicated that day 1 lysates show promise as immunodiagnostic tools. Encouraging results have been obtained with yeast lysate antigenic preparations and therefore studies in our laboratory have been directed to evaluating antigens from a number of different isolates of the fungus from human, animal and environmental sources in an effort to produce an efficient and reliable reagent for the immunodiagnosis of blastomycosis in humans and animals.

Therefore, in an effort to continue evaluations of $B$. dermatitidis yeast lysate preparations, the current study was designed to evaluate four lysate reagents (antigenic preparations from two B. dermatitidis isolates B5896 and 597, as described below, prepared by two different methods) for their ability to detect antibodies in immunized rabbits using the indirect ELISA. Sensitivity as well as specificity determinations were performed in an effort to develop an optimal immunodiagnostic antigen. 


\section{Materials \& Methods}

\subsection{Antigens}

Lysate Antigen Preparation Mycelial phase cultures of two B. dermatitidis isolates, B5896, a human isolate from Mountain Iron Minnesota and 597, a human isolate from Eagle River Wisconsin [28,29], were converted to yeast cells by culturing at $37^{\circ} \mathrm{C}$ on brain heart infusion agar. Yeast phase lysate reagents were prepared by a method similar to one that was previously used for the production of antigen from Histoplasma capsulatum [30-32] and modified in our laboratory for $B$. dermatitidis lysate antigen production [19]. The yeast phase cells were grown for 7 days at $37^{\circ} \mathrm{C}$ in a chemically defined medium in an incubator shaker, harvested by centrifugation $(700 \times$ g; 5 $\mathrm{min})$, followed by washing with distilled water, resuspended in distilled water and then allowed to lyse for 1 or 7 days at $37^{\circ} \mathrm{C}$ in water with shaking. The preparations were centrifuged, filter sterilized, merthiolate added $(1: 10,000)$ and stored at $4^{\circ} \mathrm{C}$ for further use. Protein determinations were performed on the lysates using the BCA Protein Assay Kit (Pierce Chemical Company, Rockford, $\mathrm{IL}$ ) and dilutions of the antigenic reagents used in the ELISAs assays were based on protein concentration.

\subsection{Serum Specimens}

Serum specimens were obtained from New Zealand white rabbits that were immunized intramuscularly $(2 \mathrm{ml})$ and subcutaneously $(1 \mathrm{ml})$ with $100 \mathrm{ug} / \mathrm{ml}$ of either day 1 or day 7 lysate antigens prepared from the above two $B$. dermatitidis isolates and with a $H$. capsulatum (G-17A) lysate reagent. The rabbits were bled at various intervals following immunization, but this specific study used antibodies collected at day 7 following a booster injection (same as above) on day 56.

\subsection{Enzyme-Linked Immunosorbent Assay (ELISA)}

The ability of each yeast lysate reagent to detect antibodies in the above serum specimens was determined using the indirect enzyme-linked immunosorbent assay (ELISA). Each lysate antigen was diluted $(2000 \mathrm{ng} / \mathrm{ml}$ of protein) in a carbonate-bicarbonate coating buffer $(\mathrm{pH}$ 9.6) and then added to triplicate wells (100 ul) of a Costar 96-well microplate (Fisher-Thermo). The plates were then incubated overnight at $4^{\circ} \mathrm{C}$ in a humid chamber followed by washing three times with phosphate buffered saline containing $0.15 \%$ Tween 20 (PBS-T). The serum specimens (1:2500 dilution; $100 \mathrm{ul}$ ) were added to the microplate wells and incubated for $30 \mathrm{~min}$ at $37^{\circ} \mathrm{C}$ in a humid chamber. Following this incubation the wells were washed as above and 100 ul of goat anti-rabbit IgG (H \& L) peroxidase conjugate (Kirkegaard and Perry, Gaithersburg, MD) was added to each well and incubated for 30 $\min$ at $37^{\circ} \mathrm{C}$. The plates were again washed as above and 100 ul of TMB peroxidase substrate (Pierce/FisherThermo) was added to each well and incubated for approximately $2 \mathrm{~min}$ at room temperature. The reaction was stopped by the addition of sulfuric acid and the absorbance read at $450 \mathrm{~nm}$ using a BIO-RAD 2550 EIA reader.

\section{Results}

\subsection{Reactivity of Four B. dermatitidis Antigens}

Each of the B. dermatitidis antigens prepared following yeast cell lysis for 1 day or 7 days of the two isolates (B5896 and 597) were assayed for their ability to detect antibody in serum specimens from rabbits immunized with the above 4 reagents as well as sera from rabbits immunized with $H$. capsulatum lysate reagents (G-217A/G-217B). The errors bars demonstrate the standard error of each of the trials conducted in triplicate.

When the 4 lysates were assayed against an anti-Blastomyces B5896 (day 1) specimen we determined absorbance values of 2.153 and 0.580 for the day 1 and day 7 B5896 antigens respectively, but lower values of 0.322 and 0.300 with the 597 day 1 and day 7 reagents (Figure 1).

Absorbance values of 0.617 (B5896) and 0.597 (597) were obtained with the day 1 antigens when assayed against an anti-Blastomyces B5896 (day 7) serum specimen and values of 0.499 and 0.336 were obtained with the day 7 antigens (B5896 and 597) (Figure 2).

The results shown in Figure 3, in which the 4 lysates were assayed against the anti-Blastomyces 597 (day 1) specimen, indicate that the B5896 day1 antigen demonstrated a high degree of sensitivity (absorbance value of 2.199) and a lesser amount of reactivity with the day 7 antigen (absorbance value of 1.030). In contrast lower absorbance values of 0.425 and 0.741 were seen with the 597 day 1 and day 7 antigens respectively.

When the rabbits were immunized with 597 (day 7) antigen it was determined that the B5896 and 597 day 1 antigens showed a slight increase in reactivity over both of the day 7 antigens with absorbance values of 0.722 and 0.593 respectively and values of 0.368 (B5896) and 0.437 (597) with the day 7 lysate preparations (Figure 4).

\subsection{Reactivity of B5896 with $H$. capsulatum}

Cross reactivity was evaluated by assaying the four different antigens versus anti-Histoplasma sera (strains G-217A and G-217B. Cross reactivity values indicated that the Day 7 antigens of both the B5896 and 597 reagents ranged from 0.820 to 0.781 respectively while the day 1 B5896 and 597 antigens showed considerably less cross reactivity(absorbance values of 0.390 and 0.325 ) respectively. A mean absorbance value of 1.020 was obtained when an $H$. capsulatum lysate antigen was reacted 


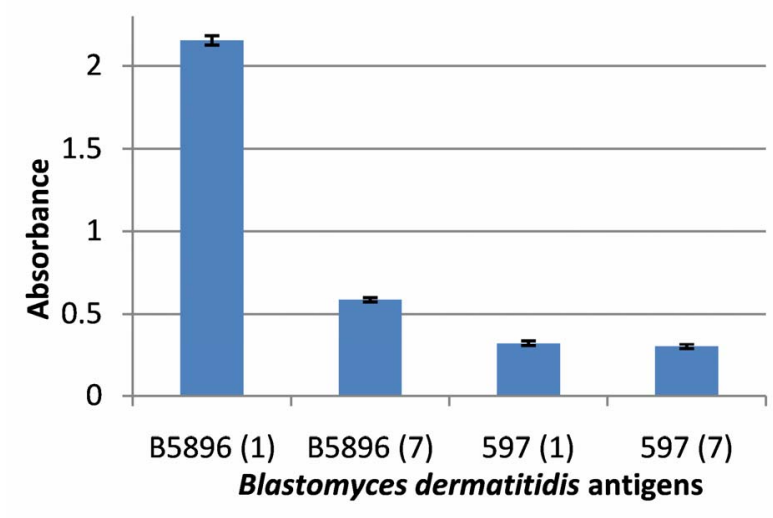

Figure 1. Reactivity of four Blastomyces dermatitidis antigens tested against the anti-Blastomyces B5896 (day 1) serum.

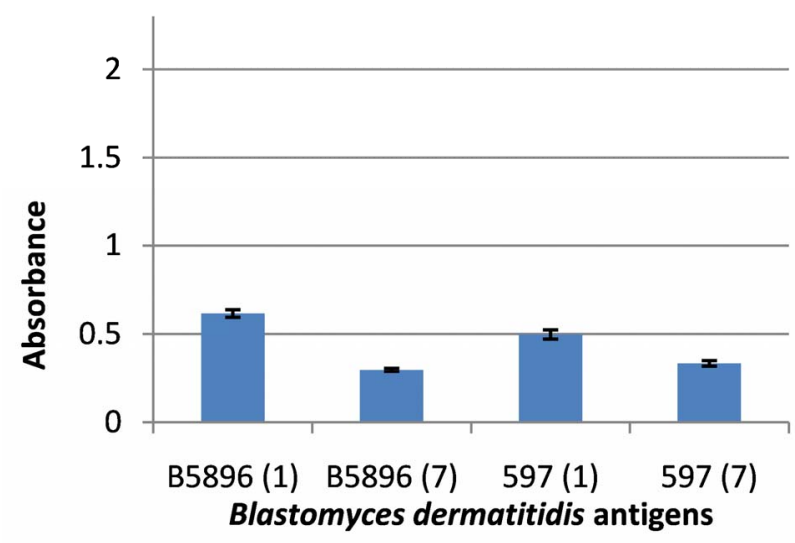

Figure 2. Reactivity of four Blastomyces dermatitidis antigens tested against the anti-Blastomyces B5896 (day 7) serum.

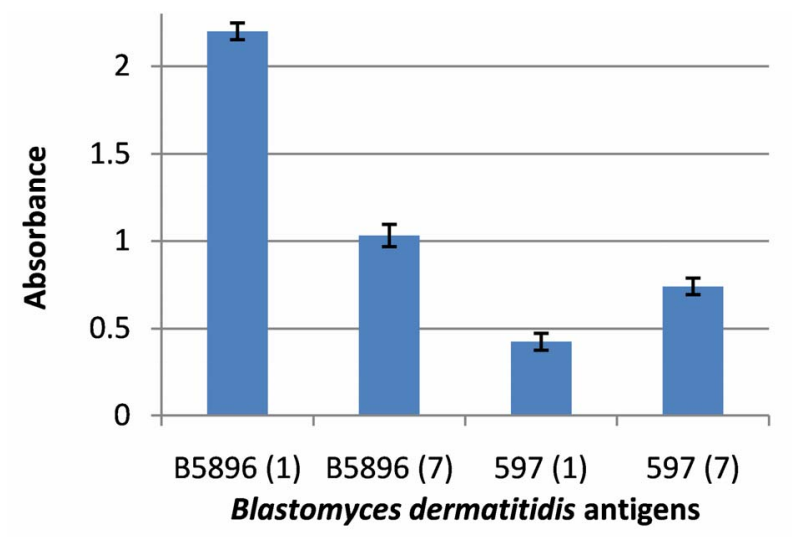

Figure 3. Reactivity of four Blastomyces dermatitidis antigens tested against the anti-Blastomyces 597 (day 1) serum.

with the anti-Histoplasma sera, which was assayed to indicate that the anti-Histoplasma serum specimens contained antibody as revealed by the $H$. capsulatum lysate antigen (Figure 5).

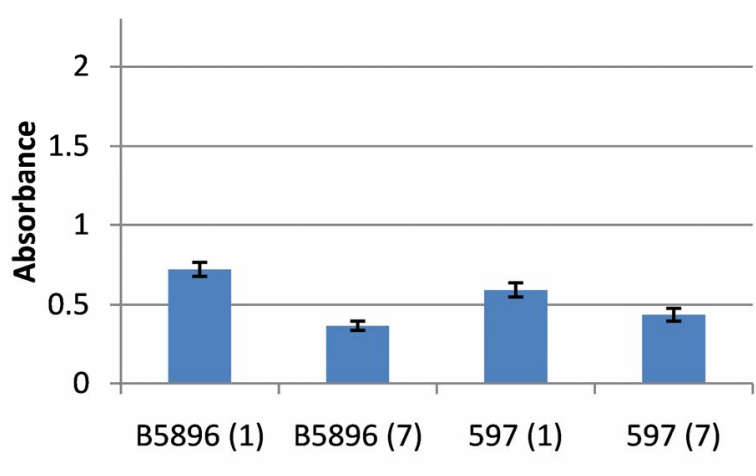

Blastomyces dermatitidis antigens

Figure 4. Reactivity of four Blastomyces dermatitidis antigens tested against the anti-Blastomyces 597 (day 7) serum.

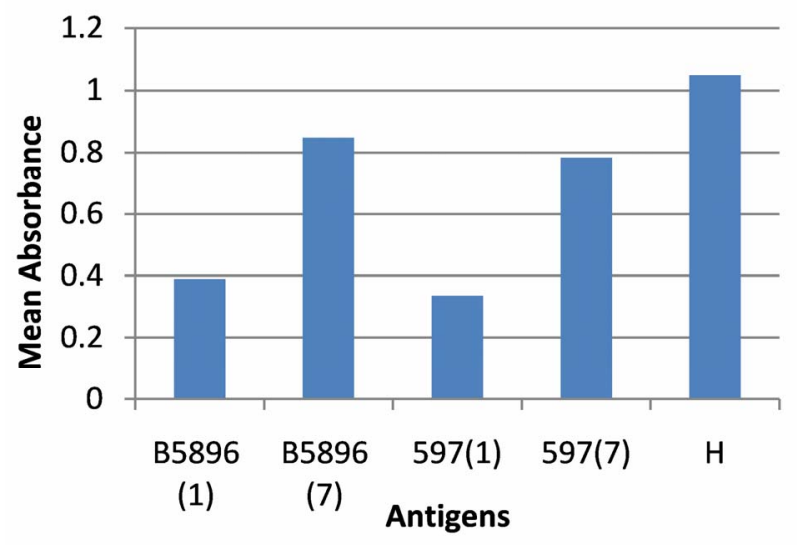

Figure 5. Cross reactivity of four $B$. dermatitidis antigens tested against the anti-Histoplasma serum.

\section{Discussion}

For a number of years our laboratory has been involved in developing $B$. dermatitidis yeast phase lysate antigens by allowing yeast cells to lyse in water for a period of 7 days [19-27]. The antigens produced by this technique varied in their sensitivity and specificity depending on the source of the $B$. dermatitidis isolate. Recently we have continued our efforts to produce and evaluate lysate antigens from various isolates of the fungus, but we also have begun to produce lysate antigens by allowing the yeast cells to lyse for different time intervals. Therefore the objective of the present study was to determine the sensitivity and specificity of lysates produced from two $B$. dermatitidis isolates (B5896 and 597) following lysis for 1 day or 7 days.

Our evaluations indicated that the day 1 preparations from both $B$. dermatitidis isolates exhibited greater reactivity than the day 7 reagents and that the B5896 day 1 lysate was optimal with regard to antibody detection in the immunized rabbit sera. With respect to specificity, 
the day 1 preparations showed considerably less cross reactivity with the anti-H. capsulatum sera than the day 7 lysates.

This could lead one to hypothesize that this may be the result of cross reactive components that develop as the yeast cells are allowed to lyse for the 7-day period. Are these cross reactive antigens intracellular components that are released following prolonged lysis? We propose additional studies using fluorescent antibodies to evaluate surface antigens versus internal antigens.

This research leads us to conclude that the B5896 strains may be valuable as a diagnostic tool for the detection of antibodies in $B$. dermatitidis infections and may also be useful for the induction of antibodies in immunized animals. These induced antibodies may then be appropriate reagents for use in antigen detection immunoassays. Evaluations are continuing in an effort to determine the efficacy of the lysates prepared from other $B$. dermatitidis isolates in order to develop a reliable antibody detection immunoassay for blastomycosis in humans and animals.

\section{Acknowledgements}

This research was supported by the Department of Biological Sciences, Idaho State University, Pocatello, ID 83209-8007 and by an Idaho State University Research Committee Grant [S119].

\section{REFERENCES}

[1] M. A. Pfaller and D. J. Diekema, "Epidemiology of Invasive Mycoses in North America," Critical Reviews in Microbiology, Vol. 36, No. 1, 2010, pp. 1-53. doi:10.3109/10408410903241444

[2] A. F. Di Salvo, "Blastomycosis,” In: Topley and Wilson's Microbiology and Microbial Infections, 9th Edition, Arnold Publishers, London, 1998, pp. 337-355.

[3] M. A. De Groote, R. Bjerke, H. Smith and L. V. Rhodes III, "Expanding Epidemiology of Blastomycosis: Clinical Features and Investigation of 2 Cases in Colorado," Clinical Infectious Diseases, Vol. 30, No. 3, 2000, pp. 582-584. doi:10.1086/313717

[4] R. W. Bradsher, "Clinical Features of Blastomycosis," Seminars in Respiratory Infections, Vol. 12, No. 3, 1997, pp. 229-234.

[5] R. W. Bradsher, S. W. Chapman and P. G. Pappas, "Blastomycosis,” Infectious Disease Clinics of North America, Vol. 17, No. 1, 2003, pp. 21-40. doi:10.1016/S0891-5520(02)00038-7

[6] J. A. Smith and C. A. Kauffman, "Pulmonary Fungal Infections,” Respirology, Vol. 17, No. 6, 2012, pp. 913-926. doi:10.1111/j.1440-1843.2012.02150.x

[7] J.A. Smith and C. A. Kauffman, "Blastomycosis," Proceedings of the American Thoracic Society, Vol. 7, No. 3, 2010, pp. 173-180.
[8] J. R. Bariola and K. S. Vyas, "Pulmonary Blastomycosis," Seminars in Respiratory Critical Care Medicine, Vol. 32, No. 6, 2011, pp. 745-753. doi:10.1055/s-0031-1295722

[9] J. A. McKinnell and P. G. Pappas, "Blastomycosis: New Insights into Diagnosis, Prevention, and Treatment," Clinical Chest Medicine, Vol. 30, No. 2, 2009, pp. 227-239. doi:10.1016/j.ccm.2009.02.003

[10] M. Saccente and G. L. Woods, "Clinical and Laboratory Update on Blastomycosis,” Clinical Microbiology Reviews, Vol. 23, No. 2, 2010, pp. 367-381. doi:10.1038/nrmicro1537

[11] J. E. Cutler, G. S. Deepe Jr. and B. S. Klein, “Advances in Combating Fungal Diseases: Vaccines on the Threshold,” Nature Review of Microbiology, Vol. 5, No. 1, 2007, pp. 13-28.

[12] K. S. Vyas, J. R. Bariola and R. W. Bradsher, "Advances in the Serodiagnosis of Blastomycosis," Current Fungal Infection Reports, Vol. 2, No. 4, 2008, pp. 227-231. doi:10.1007/s12281-008-0033-Z

[13] B. S. Klein and J. M. Jones, "Isolation, Purification and Radiolabeling of a Novel 120-kD Surface Protein on Blastomyces dermatitidis Yeasts to Detect Antibody in Infected Patients,” Journal of Clinical Investigation, Vol. 85, No. 1, 1990, pp. 152-161. doi:10.1172/JCI114406

[14] P. Connolly, C. A. Hage, J. R. Bariola, E. Bensadoun, M. Rodgers, R. W. Bradsher and J. J. Wheat, "Blastomyces dermatitidis Antigen Detection by Quantitative Enzyme Immunoassay," Clinical Vaccine Immunology, Vol. 19, No. 1, 2012, pp. 53-56. doi:10.1128/CVI.05248-11

[15] C. A. Hage, T. E. Davis, L. Egan, M. Parker, D. Fuller, A. M. LeMonte, D. Durkin, P. Connelly, L. J. Wheat, D. Blue-Hindy and K. A. Knox, "Diagnosis of Pulmonary Histoplasmosis and Blastomycosis by Detection of Antigen in Bronchoalveolar Lavage Fluid Using an Improved Second-Generation Enzyme-Linked Immunoassay,” Respiratory Medicine, Vol. 101, No. 1, 2007, pp. 43-47. doi:10.1016/j.rmed.2006.04.017

[16] B. S. Klein, R. A. Squires, J. K. Lloyd, D. R. Ruge and A. M. Legendre, "Canine Antibody Response to Blastomyces dermatitidis WI-1 Antigen," American Review of Veterinary Research, Vol. 61, No. 5, 2000, pp. 554-558.

[17] D. Spector, A. M. Legendre, J. Wheat, D. Bemis, B. Rohrbach, J. Taboada and M. Durkin, “Antigen and Antibody Testing for the Diagnosis of Blastomycosis in Dogs,” Journal of Veterinary Internal Medicine, Vol. 22, No. 4, 2008, pp. 839-843. doi:10.1111/j.1939-1676.2008.0107.x

[18] J. R. Bariola, C. A. Hage, M. Durkin, E. Bensadoun, P. O. Gubbins, L. J. Wheat and R. W. Bradsher, "Detection of Blastomyces dermatitidis Antigen in Patients with Newly Diagnosed Blastomycosis,” Diagnostic Microbiology and Infectious Diseases, Vol. 69, No. 2, 2011, pp. 187-191. doi:10.1016/j.diagmicrobio.2010.09.015

[19] S. M. Johnson and G. M. Scalarone, "Preparation and ELISA Evaluation of Blastomyces dermatitidis Yeast Phase Lysate Antigens," Diagnostic Microbiology and Infectious Diseases, Vol. 11, No. 2, 1988, pp. 81-86. doi:10.1016/0732-8893(88)90076-4

[20] J. L. Bono, A. M. Legendre and G. M. Scalarone, "Detec- 
tion of Antibodies and Delayed Hypersensitivity with Rotofor Preparative IEF Fractions of Blastomyces dermatitidis Yeast Phase Lysate Antigens," Journal of Medical and Veterinary Mycology, Vol. 33, No. 4, 1995, pp. 209214. doi:10.1080/02681219580000441

[21] M. A. Fisher, J. L. Bono, R. O. Abuodeh, A. M. Legendre and G. M. Scalarone, "Sensitivity and Specificity of an Isoelectric Focusing Fraction of Blastomyces dermatitidis Yeast Lysate Antigen for the Detection of Canine Blastomycosis,” Mycoses, Vol. 38, No. 5-6, 1995, pp. 177-182. doi:10.1111/j.1439-0507.1995.tb00046.x

[22] R. C. Axtell and G. M. Scalarone, "Serological Differences in three Blastomyces dermatitidis Strains," Mycoses, Vol. 45, No. 11-12, 2002, pp. 437-442.

[23] J. F. Shurley, A. M. Legendre and G. M. Scalarone, "Blastomyes dermatitidis Antigen Detectioni in Urine Specimens from Dogs with Blastomycosis Using a Competitive Binding Inhibition ELISA,” Mycopathologia, Vol. 160, No. 2, 2005, pp. 137-142. doi:10.1007/s11046-005-3153-9

[24] J. F. Shurley and G. M. Scalarone, "Isoelectric Focusing and ELISA Evaluation of a Blastomyces dermatitidis Human Isolate,” Mycopathologia, Vol. 164, No. 2, 2007, pp. 73-76. doi:10.1007/s11046-007-9033-8

[25] C. M. Sestero and G. M. Scalarone, "Detection of IgG and IgM in Sera from Canines with Blastomycosis Using Eight Blastomyces dermatitidis Yeast Phase Lysate Antigens,” Mycopathologia, Vol. 162, No. 1, 2006, pp. 33-37. doi:10.1007/s11046-006-0028-7

[26] C. M. Sestero and G. M. Scalarone, "Detection of the Surface Antigens BAD-1 and Alpha-(1,3)-Glucan in Six Different Strains of Blastomyces dermatitidis Using Mono- clonal Antibodies," Journal of Medical and Biological Science, Vol. 1, No. 1, 2006, pp. 1-7.

[27] W. O. Hatch and G. M. Scalarone, "Comparison of Colorimetric and Chemiluminescent ELISAs for the Detection of Antibodies to Blastomyces dermatitidis," Journal of Medical and Biological Sciences, Vol. 3, No. 1, 2009, pp. 1-6.

[28] Minnesota Department of Health, "Minnesota Department of Health Disease Control Newsletter," Blastomycosis, Vol. 31, No. 4, 2003, pp. 1-6.

[29] B. S. Klein, J. M. Vergeront, R. J. Weeks, U. N. Kumar, G. Mathai, B. Varkey, L. Kaufman, R. W. Bradsher, J. R. Stoebig and J. P. Davis, "Isolation of Blastomyces dermatitidis in Soil Associated with a Larger Outbreak of Blastomycosis in Wisconsin," Journal of Infectious Diseases, Vol. 155, No. 2, 1986, pp. 262-268. doi:10.1093/infdis/155.2.262

[30] H. B. Levine, G. M. Scalarone and S. D. Chaparas, "Preparation of Fungal Antigens and Vaccines: Studies on 'Coccidioides immitis' and 'Histoplasma capsulatum',' Contributions to Microbiology and Immunology, Vol. 3, 1977, pp. 106-125.

[31] G. M. Scalarone, H. B. Levine and S. D. Chaparas, "Delayed Hypersensitivity Responses of Experimental Animals to Histoplasmin from the Yeast and Mycelial Phases of Histoplasma capsulatum," Infection and Immunity, Vol. 21, No. 3, 1978, pp. 705-713.

[32] H. B. Levine, G. M. Scalarone, G. D. Campbell, R. C. Graybill and S. D. Chaparas, "Histoplasmin-CYL, a Yeast Phase Reagent in Skin Test Studies in Humans," American Review of Respiratory Diseases, Vol. 119, No. 4, 1979, pp. 629-636. 